\title{
Characterization of different oligomeric forms of CRISP2 in the perinuclear theca versus the fibrous tail structures of boar spermatozoa ${ }^{\dagger}$
}

\author{
M. Zhang ${ }^{1}$, E.G. Bromfield ${ }^{1,2}$, T. Veenendaal ${ }^{3}$, J. Klumperman ${ }^{3}$, \\ J.B. Helms ${ }^{1}$ and B.M. Gadella ${ }^{1,4, *}$
}

${ }^{1}$ Department of Biomolecular Health Sciences, Faculty of Veterinary Medicine, Utrecht University, The Netherlands, ${ }^{2}$ Priority Research Centre for Reproductive Science, University of Newcastle, New South Wales, Australia, ${ }^{3}$ Section Cell Biology, Center for Molecular Medicine, University Medical Center Utrecht, Utrecht University, The Netherlands and ${ }^{4}$ Department of Farm Animal Health, Faculty of Veterinary Medicine, Utrecht University, Utrecht, The Netherlands

*Correspondence: Yalelaan 2, 3584 CM Utrecht, The Netherlands. Tel: +31-30-2535386; E-mail: b.m.gadella@uu.nl

${ }^{\dagger}$ Grant Support: MZ is financed by the China Scholarship Council (CSC) (No.201606170117). EGB is recipient of an NHMRC CJ Martin Early Career Fellowship (APP1138701). The electron microscopy lab of JK is part of the National Roadmap for Large-Scale Research Infrastructure 2017-2018, project number 184.034.014, (partly) financed by the Dutch Research Council (NWO). Confocal microscopy was performed at the Center of Cell Imaging of the Faculty of Veterinary Medicine under supervision of Dr. R. Wubbolts and Ing. E. van 't Veld.

Received 6 January 2021; Revised 30 April 2021; Accepted 20 June 2021

\begin{abstract}
Mammalian sperm carry a variety of highly condensed insoluble protein structures such as the perinuclear theca, the fibrous sheath and the outer dense fibers, which are essential to sperm function. We studied the role of cysteine rich secretory protein 2 (CRISP2); a known inducer of non-pathological protein amyloids, in pig sperm with a variety of techniques. CRISP2, which is synthesized during spermatogenesis, was localized by confocal immunofluorescent imaging in the tail and in the post-acrosomal region of the sperm head. High-resolution localization by immunogold labeling electron microscopy of ultrathin cryosections revealed that CRISP2 was present in the perinuclear theca and neck region of the sperm head, as well as in the outer dense fibers and the fibrous sheath of the sperm tail. Interestingly, we found that under native, nonreducing conditions CRISP2 formed oligomers both in the tail and the head but with different molecular weights and different biochemical properties. The tail oligomers were insensitive to reducing conditions but nearly complete dissociated into monomers under $8 \mathrm{M}$ urea treatment, while the head $250 \mathrm{kDa}$ CRISP2 positive oligomer completely dissociated into CRISP2 monomers under reducing conditions. The head specific dissociation of CRISP2 oligomer is likely a result of the reduction of various sulfhydryl groups in the cysteine rich domain of this protein. The sperm head CRISP2 shared typical solubilization characteristics with other perinuclear theca proteins as was shown with sequential detergent and salt treatments. Thus, CRISP2 is likely to participate in the formation of functional protein complexes in both the sperm tail and sperm head, but with differing oligomeric organization and biochemical properties. Future studies will be devoted to the understand the role of CRISP2 in sperm protein complexes formation and how this contributes to the fertilization processes.
\end{abstract}




\section{Summary sentence}

\section{Biochemical properties of CRISP2 oligomers in boar spermatozoa.}

Key words: CRISP-2, protein oligomers, fibrous sheath, outer dense fibers, perinuclear theca, pig sperm.

\section{Introduction}

Cysteine-rich secretory proteins (CRISPs) are members of the CAP (CRISPs, antigen 5- and pathogenesis-related protein 1) superfamily that are expressed in all eukaryotes. The CAP family proteins have been widely implicated in many physiological and pathological processes including immunity, venom toxicity, reproduction and cancer biology [1-3]. Evolutionary studies have revealed that the CRISP subfamily are only found in amniotes [4, 5]. In reptiles, CRISPs are found in venoms and many snake venom CRISPs have been characterized in the last decades [4, 5]. In mammals, three paralogues of four CRISP members have been described: CRISP1, CRISP2, CRISP3 and CRISP4, with CRISP4 only found in some rodent species [6]. These proteins are $20-30 \mathrm{kDa}$ in size, and share an N-terminal CAP domain containing four conserved motifs and a C-terminal cysteine-rich domain connected with a hinge [1,7].

Mammalian CRISPs are highly expressed in male reproductive tract tissues where CRISP1 and CRISP4 are secreted by epithelial cells lining the ductus epididymis, while CRISP2 expression is initiated during spermatogenesis in the testis [8]. CRISP3 is known to be secreted into seminal plasma by epithelial cells from accessory gland such as the prostate and the seminal vesicle [9]. Importantly, double knock out (DKO) Crisp1/Crisp4 mice demonstrate a male subfertility phenotype [10], while a similar DKO model indicated a decreased sperm motility phenotype without a loss of fertility [11]. Numerous studies have shown that CRISP3 expression is significantly increased in prostate cancer cells and is a valuable maker for prostate cancer prognosis [12-15].

Gene manipulation studies of CRISP2 have recently revealed that CRISP2 is important for sperm motility, sperm-egg fusion and male fertility. Crisp2 knockout mice showed a significant fertility dysfunction phenotype [16] as the sperm they produce have lower acrosome reaction rates in response to progesterone and show an altered flagellum beating pattern [17]. In line with this, low expression levels of CRISP2 are observed in sperm from asthenoteratozoospermia patients and is proposed as a causal factor of male infertility [18-20].

One rationale for why CRISP2 defects may affect male fertility lies in observation that CRISP2 is the sole CRISP that is expressed during the early stages of spermiogenesis where CRISP2 mRNA undergoes a significant translational delay before CRISP2 protein is incorporated in to the developing sperm head and tail $[17,21]$. Unlike other mammalian CRISPs, CRISP2 gene expression is not dependent on androgen regulation, nor is the protein posttranslationally modified by glycosylation [22]. CRISP2 shows a conserved localization pattern in the sperm acrosome, connecting piece and the outer dense fibers of the sperm tail among human, mouse and guinea pig spermatozoa [21, 23, 24]. Notably, in human sperm, CRISP2 is released from the acrosome and reoriented at the equatorial segment after the acrosome reaction, suggesting a possible involvement in the orchestration of sperm-egg fusion [23]. Human sperm CRISP2 protein is detected as a $25 \mathrm{kDa}$ band on immunoblots and it is stably associated with sperm pellet in acidic medium, but is known to be completely soluble when held in a medium at $\mathrm{pH} 11$ [23]. Two forms of CRISP2: 25 and $27 \mathrm{kDa}$ are present in the rat sperm acrosome and outer dense fibers [21].
Mammalian sperm carry a variety of highly condensed insoluble protein structures such as the perinuclear theca (PT). This cytoskeletal structure flanks the nucleus of mammalian mature sperm. It can be divided into two structurally continuous but functionally distinct regions: the sub-acrosomal layer (SAL) and the post-acrosomal sheath (PAS) $[25,26]$. Proteins of the SAL reside between the inner acrosomal membrane and the nuclear envelope at the equatorial segment region of the sperm head, while posterior from the acrosome, proteins reside between the plasmalemma and the nuclear envelope making up the PAS [26]. Dozens of proteins have been identified as constituents of the PT of mammalian sperm over the last decades, however the function of the PT during and following fertilization is largely unknown. Besides the PT, also insoluble protein aggregates have been observed in the acrosome [27-29]. Moreover, two other insoluble protein aggregates are observed in the sperm tail, where the axoneme is surrounded by 9 outer dense fiber structures and in the principle piece of the sperm tail the axoneme and these outer dense fibers (ODF) are also surrounded by the fibrous sheath (FS) [30]. These two structures serve the longitudinal and radial properties of the sperm flagellum for effective and efficient motility required to fertilize the egg. From previous studies, it is known that all the above mentioned highly condensed non-soluble sperm protein structures contain CRISP2 [21]. Of specific interest in this context is the property of CAP proteins such as CRISP2 (and other CRISP proteins) to form protein oligomers [31]. While little is known regarding this oligomer formation, the CAP domain of CRISP proteins may enable this [32], and the cysteine rich region of the protein may also be involved in protein aggregate formation in a redox sensitive manner [33-35]. Despite these intriguing leads, the involvement of CRISP2 in the diverse insoluble condensed protein structures in spermatozoa has not been addressed biochemically. Therefore, we have investigated the localization and organization of CRISP2 in boar sperm by (i) using immunolabeling techniques combined with both confocal and transmission electron microscopy, (ii) isolating the diverse protein dense structures and to determine the oligomeric organization of CRISP2 under reducing and non-reducing conditions and (iii) investigating the dissociation of CRISP2 under high urea conditions.

\section{Materials and methods}

\section{Reagents and antibodies}

All chemicals were obtained from Sigma (St. Louis, MO, USA) unless otherwise stated. The goat polyclonal antibody against CRISP2 (aa77-89) (Cat\#: MBS422304) and paired CRISP2 blocking peptide (Cat\#: MBS427212) were obtained from MyBiosource (San Diego, CA, USA). The rabbit polyclonal antibody against CRISP2 (Cat\#: 19066-1-A) was obtained from Proteintech (Chicago, IL, USA) and the mouse anti $\alpha$-tubulin monoclonal antibody was purchased from Sigma (Cat\#: T5168).

\section{Boar sperm preparation}

Semen was collected over gauze to remove gelatinous materials and debris. The collected semen from highly fertile boars was diluted 
to 20 million sperm $/ \mathrm{mL}$ in a commercial diluter and packed in insemination tubes of $80 \mathrm{~mL}$ and transported at $17^{\circ} \mathrm{C}$ to our lab by a courier from a commercial breeder (Cooperative Center for Artificial Insemination in Pigs, Veghel, the Netherlands) and stored in a cool box $\left(17^{\circ} \mathrm{C}\right)$ until use. Sperm quality was established by evaluating motility, viability, concentration, and morphological parameters. Sperm cells were washed through a discontinuous Percoll (GE Healthcare, Piscataway, NJ, USA) gradients consisting of $4 \mathrm{~mL} 35 \% \mathrm{v} / \mathrm{v}$ and $2 \mathrm{~mL} 70 \% \mathrm{v} / \mathrm{v}$ Percoll in HEPES-buffered saline (HBS: $20 \mathrm{mM}$ HEPES, $137 \mathrm{mM} \mathrm{NaCl}, 10 \mathrm{mM}$ glucose, $2.5 \mathrm{mM} \mathrm{KCl}, 0.1 \%$ kanamycin, $\mathrm{pH} 7.6)$ at $750 \times g$ for $15 \mathrm{~min}$ at room temperature (RT) using MIKRO 200 (Hettich, Tuttlingen, Germany). The top and interface layers were removed and sperm pellets were further washed in phosphate buffered saline (PBS), (137 mM $\mathrm{NaCl}, 8.0 \mathrm{mM}$ Na2HPO4.2H2O, $1.5 \mathrm{mM} \mathrm{KH} 2 \mathrm{PO} 4,2.7 \mathrm{mM} \mathrm{KCl}$, $\mathrm{pH} 7.4)$ at $750 \times \mathrm{g}$ for $10 \mathrm{~min}$, at RT. All solutions were iso-osmotic (290-300 $\mathrm{mOsm} / \mathrm{kg}$ ) and at RT before use.

\section{Isolation of sperm heads and tails}

Percoll washed sperm cells $\left(1 \times 10^{8}\right)$ were resuspended in $1.5 \mathrm{~mL}$ PBS and $1 \mathrm{mM}$ phenylmethylsulfonyl fluoride (PMSF) was added to protect against protein degradation. Sperm in solution were sonicated on ice at nine microns using an MSE (East Sussex, UK) Ltd Soniprep 150 sonicator at 15 -s bursts with 45 -s interval, three cycles until $>99 \%$ of all sperm heads and tails were dissociated. Sonicated sperm heads and tails were separated through a $62 \%(\mathrm{w} / \mathrm{v})$ sucrose gradient in $10 \mathrm{mM}$ Tris- $\mathrm{HCl}(\mathrm{pH} \mathrm{7.4})$ at $50000 \mathrm{rpm}$ and a temperature of $4^{\circ} \mathrm{C}$ for 90 min using a SW 60Ti swinging-bucket rotor (Beckman, Mississauga, Canada). This ultracentrifugation step resulted in the pelleting of the heads, which are denser than the sucrose, at the centrifugal bottom of the tube and the tails can then be collected from the interface between the solution and the sucrose. The sperm heads and tails were collected and placed in separate tubes, washed twice with PBS at $14000 \times g$, at $4^{\circ} \mathrm{C}$ for $20 \mathrm{~min}$ using MIKRO 200R (Hettich, Tuttlingen, Germany), and then used directly or frozen at $-80^{\circ} \mathrm{C}$ for later use.

\section{Isolation of PT proteins from the sonicated boar sperm head}

Perinuclear theca proteins from the boar sperm head were isolated as previously described $[36,37]$. Purified sperm heads were first extracted in $0.2 \%(\mathrm{v} / \mathrm{v})$ Triton X-100 for $1 \mathrm{~h}$ at RT with agitation. Following the incubations, the solution was then subjected to centrifugation at $2500 \times \mathrm{g}$ for $10 \mathrm{~min}$ at RT and the resulting supernatants were recovered. The pellets were then extracted in $1 \mathrm{M}$ $\mathrm{KCl}$ as the first step extraction. After washing, the pellets were then extracted in $0.1 \mathrm{M} \mathrm{NaOH}$ overnight at $4^{\circ} \mathrm{C}$ with agitation. PT proteins were then retrieved from the alkaline extraction supernatants. The resulting pellets were washed twice with PBS before the next extraction and/or before being solubilized in sodium dodecyl sulfate (SDS) sample buffer/fixed in 4\% paraformaldehyde (PFA) for immunostaining.

\section{Detergent fractionation of sperm heads and tails}

Purified, sonicated sperm heads were subjected to serial extractions to investigate CRISP2 extractability as previously reported [37].
Briefly, sonicated sperm heads were first extracted in $1 \%(\mathrm{v} / \mathrm{v})$ NP-40 at RT with agitation for 2 h. Following the incubations, the solution was subjected to centrifugation at $2500 \times g$, at RT for $10 \mathrm{~min}$ and the resulting supernatants were recovered. The pellets were then extracted in $1 \%(\mathrm{w} / \mathrm{v})$ SDS for $2 \mathrm{~h}$, at RT, with agitation. The resulting pellets were washed twice with PBS before the next extraction and/or before being solubilized in SDS sample buffer.

Purified sperm tails were incubated in $1 \%(\mathrm{v} / \mathrm{v})$ Triton X-100 (50 mM HEPES, $150 \mathrm{mM} \mathrm{NaCl}$, pH 7.2, 1\%Triton X-100) on ice or SDS-EDTA buffer (1\% SDS, $75 \mathrm{mM} \mathrm{NaCl}, 24 \mathrm{mM}$ EDTA, $\mathrm{pH}$ 6.0) for $30 \mathrm{~min}$ at RT and centrifuged at $14000 \times \mathrm{g}$, for $15 \mathrm{~min}$. Soluble and insoluble fractions were collected, respectively. Insoluble pellets were further denatured in $2 \times$ SDS sample buffer $(100 \mathrm{mM}$ Tris, $\mathrm{pH} 6.8$, 4\% SDS, $0.04 \%$ bromophenol blue, $20 \%$ glycerol, $5 \%$ $\beta$-mercapto-ethanol) and boiled for $10 \mathrm{~min}$. For an additional experiment, sperm tails were directly solubilized in $2 \times$ SDS sample buffer (for details see Immunoblotting), boiled for $10 \mathrm{~min}$ or solubilized in $8 \mathrm{M}$ urea (in $2 \times$ SDS sample buffer), without heating.

\section{Blue native PAGE and native blots}

The sperm head and tail fractions were extracted in $1 \%(\mathrm{v} / \mathrm{v})$ Triton X-100 (50 mM HEPES, $150 \mathrm{mM} \mathrm{NaCl}$, pH 7.2, 1\% Triton $\mathrm{X}-100$ ) for $30 \mathrm{~min}$ on ice, followed by a $15 \mathrm{~min}$ centrifugation at $14000 \mathrm{~g}, 4^{\circ} \mathrm{C}$. Supernatants were recovered and mixed with $4 \times$ Native Sample Buffer ( $400 \mathrm{mM}$ Tris HCl, pH 8.6, 40\% glycerol, $0.04 \%$ Brom-phenol-Blue) and 5\% G-250 sample additive (Cat\#: BN2004, Thermo Scientific) before loading onto a 4-20\% MiniPROTEAN TGX Precast Gels (Cat\#: 4561094, Bio-Rad). Native running buffer (25 mM Tris base, $192 \mathrm{mM}$ glycine, $\mathrm{pH} 8.3$ ) and native PAGE cathode buffer additive (20X) (Cat\#: BN2002, Thermo Scientific) were used to make cathode running buffer following the manufacturer's instruction. Electrophoresis was carried out at $150 \mathrm{~V}$, RT for $2 \sim 2.5$ h. Gels were either stained with Coomassie R-250 or prepared for native blots.

Native blots were performed as normal Western blots with the exception that Tris-Glycine Transfer Buffer (12 mM Tris base, $96 \mathrm{mM}$ glycine, $\mathrm{pH}$ 8.3) was used. Proteins were blotted onto polyvinylidene difluoride (PVDF) membrane (GE Healthcare) at $25 \mathrm{~V}, \mathrm{RT}$ for $1 \mathrm{~h}$. After transfer, blotting membranes were fixed in $8 \%(\mathrm{v} / \mathrm{v})$ acetic acid for $15 \mathrm{~min}$ and rinsed with water, then air dried overnight, RT. Dried membranes were rewet in methanol to remove excessive bound dye. After rinsing with water, membranes continued as normal western blots immunodetection (see section Immunoblotting). NativeMark unstained protein standard (Thermo Scientific) was used to estimate protein size.

\section{Immunoblotting}

Before loading on to an SDS-PAGE gel (5\% stacking gel, $12 \%$ running gel), protein extracts were denatured in $4 \times$ SDS sample buffer $(200 \mathrm{mM}$ Tris-HCl, $\mathrm{pH} 6.8,10 \% \beta$-mercapto-ethanol, $8 \%$ SDS, $0.08 \%$ bromophenol blue, $40 \%$ glycerol) and boiled for $10 \mathrm{~min}$. Under non-reducing conditions, $\beta$-mercapto-ethanol was omitted. Proteins were wet blotted onto $0.45 \mu \mathrm{m}$ nitrocellulose membranes (GE Healthcare, Piscataway, NJ, USA) at $100 \mathrm{~V}$ for $1 \mathrm{~h}$. After blocking for $3 \mathrm{~h}$ at RT in $5 \%(\mathrm{w} / \mathrm{v})$ BSA in PBS with $0.05 \%(\mathrm{v} / \mathrm{v})$ Tween-20 (PBST), membranes were incubated with primary antibodies (diluted in PBST with $1 \%$ BSA) overnight at $4^{\circ} \mathrm{C}$. Immunizing peptide solution was made with five times concentrated blocking peptide to antibody weight with agitation at RT for $1 \mathrm{~h}$ before 

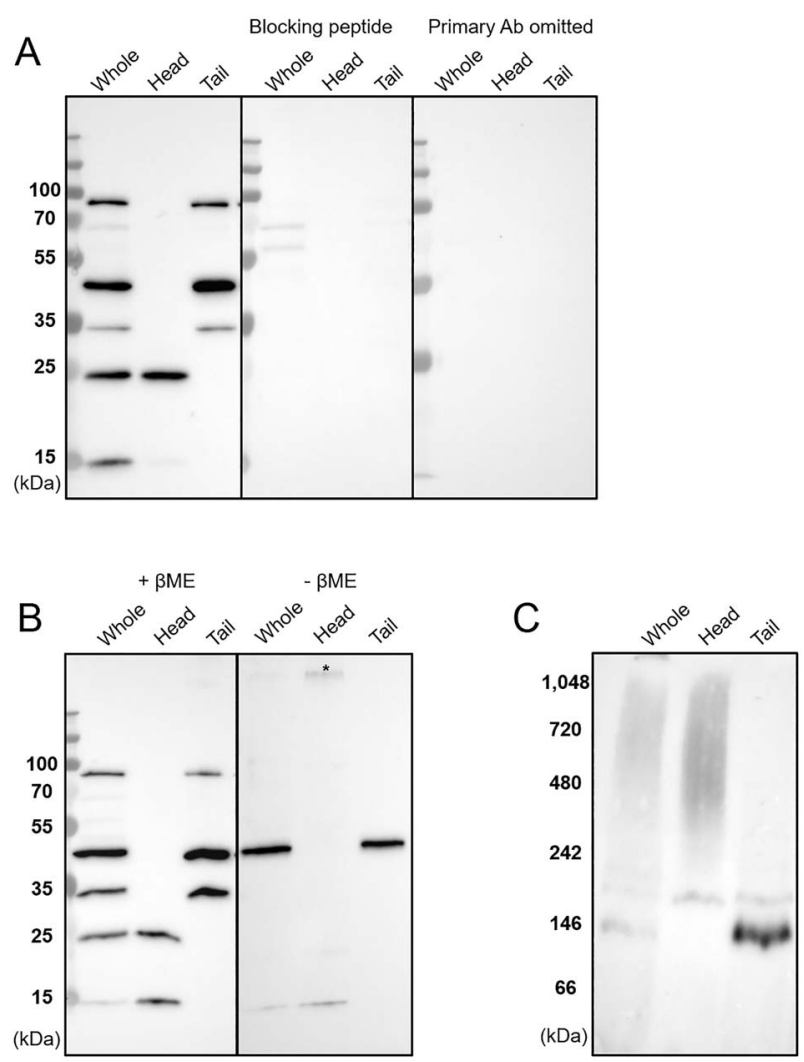

Figure 1. CRISP2 is present as multimers in boar sperm. (A) Western blots of CRISP2 on the extracts from whole sperm cells, sperm heads and sperm tails. (B) Western blots of CRISP2 on the extracts from sperm heads and sperm tails with or without $\beta$-mercapto-ethanol ( $\beta \mathrm{ME}$ ). There was a positive band ( $>\sim 250 \mathrm{kDa}$, asterisk) observed in the head fraction in the absence of $\beta \mathrm{ME}$. (C) Native blots showing that CRISP2 was participating in a $\sim 200 \mathrm{kDa}$ protein complex in the sperm head and was involved in two complexes: $\sim 150$ and $\sim 200 \mathrm{kDa}$ in the tail fraction. The immunoreactivity of all the detected bands were absent when the CRISP2 primary Ab (goat polyclonal) was preincubated with blocking peptide or omitted. Migration of molecular mass standards are sized in $\mathrm{kDa}$.

incubating with membranes. After three washes in PBST for $15 \mathrm{~min}$, membranes were incubated with horse radish peroxidase (HRP) conjugated secondary antibodies (mouse anti-goat HRP IgG, Cat\#: 2354, Santa Cruz, CA, USA; goat anti-rabbit and mouse HRP IgG, Cat\#: P0448, Agilent) for $1 \mathrm{~h}$ at RT. After rinsing four times in PBST for $20 \mathrm{~min}$, membranes were developed using chemiluminescence (ECL-detection kit; Supersignal West Pico, Pierce, Rockford IL, USA). Migration levels of proteins were visualized using PageRuler Plus pre-stained protein ladder, 10 to $250 \mathrm{kDa}$ (Thermo Scientific).

\section{Indirect immunofluorescence staining}

Sperm cells were fixed in $4 \%$ PFA for $15 \mathrm{~min}$ at RT, then $20 \mu \mathrm{L}$ of the sperm suspension was deposited on Superfrost slides (Thermo Scientific) and covered with coverslips, then dried at RT for $20 \mathrm{~min}$. Coverslips were floated with PBS and removed. For permeabilization, sperm cells were permeabilized using $0.5 \%(\mathrm{v} / \mathrm{v})$ Triton X-100 for $15 \mathrm{~min}$, at RT. After rinsing with PBS, slides were blocked with $1 \%(\mathrm{w} / \mathrm{v})$ BSA in PBS for $1 \mathrm{~h}$ at RT, incubated overnight at $4{ }^{\circ} \mathrm{C}$ with a CRISP2 antibody (1:250 in $1 \%$ BSA). Slides were washed again before incubation for $1 \mathrm{~h}$ at RT with
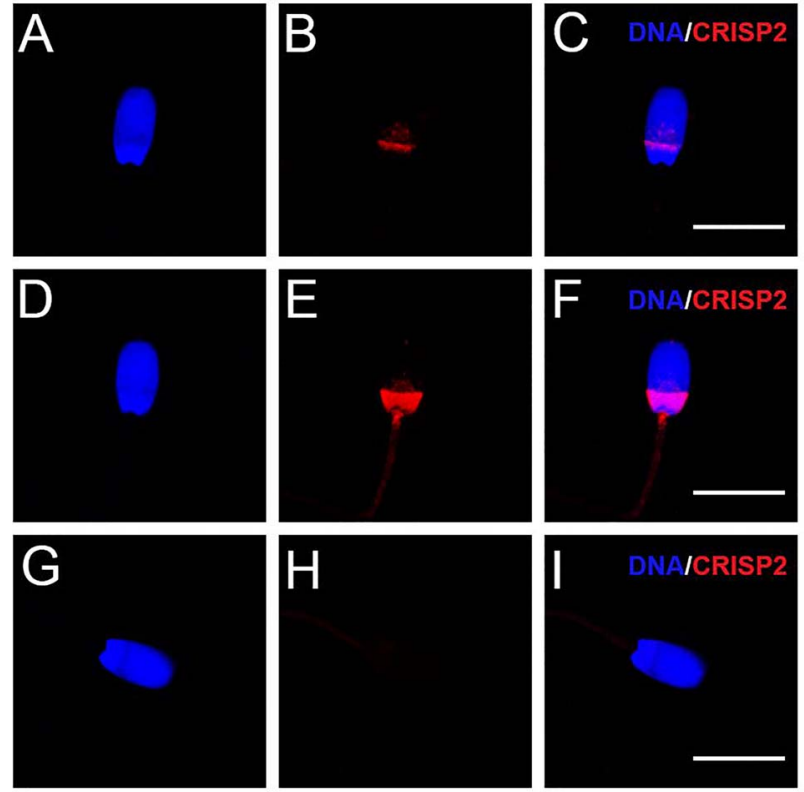

Figure 2. Immunofluorescent staining of CRISP2 in boar sperm. Percoll washed sperm cells were fixed in $4 \%$ paraformaldehyde (PFA). (A-C) No permeabilization after fixation. (D-I) Permeabilized after fixation with $0.5 \%$ Triton X-100. (A, D) Hoechst 33342 staining, (B, E) CRISP2 immune labeling and $(C, F)$ merge of both fluorescence. (G) Hoechst 33342 staining. (H) CRISP2 immune labeling after pre-incubation of the CRISP2 antibody with a blocking peptide. (I) merge of $\mathrm{G}$ and $\mathrm{H}$ fluorescence. Distance bar $=10 \mu \mathrm{m}$.

either Alexa Fluor 568-conjugated donkey anti-goat $\operatorname{IgG}[\mathrm{H}+\mathrm{L}]$ (Cat\#: A-11057, Thermo Scientific) or donkey anti-rabbit $\mathrm{IgG}$ $[\mathrm{H}+\mathrm{L}](\mathrm{Cat \#}: \mathrm{A}-10042$, Thermo Scientific) and counterstaining with Hoechst 33342 (1ug/mL, Sigma) for $10 \mathrm{~min}$, at RT. After extensive washing with PBS, slides were mounted with FluorSave reagent (Cat\#: 345789, Merck Millipore) and covered with coverslips. For negative controls, the primary antibody was either pre-incubated with CRISP2 blocking peptide or the primary antibody was omitted. Observations were performed on a Leica SPE-II confocal microscope using a $63 \times$ objective (NA 1.3, HCX PLANAPO oil) and images were analyzed by evaluating the fluorescence intensity for CRISP2 and DNA (Hoechst33342) in each channel using Image J software (bundled with 64-bit Java 1.8.0_172, National Institutes of Health, Bethesda, MD, USA).

\section{Immunogold labeling}

Percoll washed sperm cells $\left(10 \times 10^{6}\right)$ were resuspended in $0.5 \mathrm{~mL}$ PBS, mixed with equal volume of $4 \%$ paraformaldehyde (PFA) (Electron Microscopy Sciences) and fixed for $5 \mathrm{~min}$ at RT. The fixative was removed by centrifugation at $750 \times g$, for $5 \mathrm{~min}$ at RT. Fresh $4 \%$ PFA was added and cells were fixed overnight. $4 \%$ PFA was then replaced with $1 \%$ PFA and cells were stored at $4^{\circ} \mathrm{C}$. Further processing of samples for ultrathin cryosectioning and immuno-labeling according to the protein A-gold method was performed as described previously [38]. In brief, fixed cells were washed with $0.05 \mathrm{M}$ glycine in PBS, resuspended and pelleted in $12 \%$ gelatin in $\mathrm{PBS}$ at $37^{\circ} \mathrm{C}$. The cell pellet was solidified on ice and cut into small blocks. For cryoprotection, blocks were infiltrated overnight with $2.3 \mathrm{M}$ sucrose at $4^{\circ} \mathrm{C}$, then mounted on aluminum pins and frozen in liquid nitrogen. A 1:1 mixture of $2.3 \mathrm{M}$ sucrose 

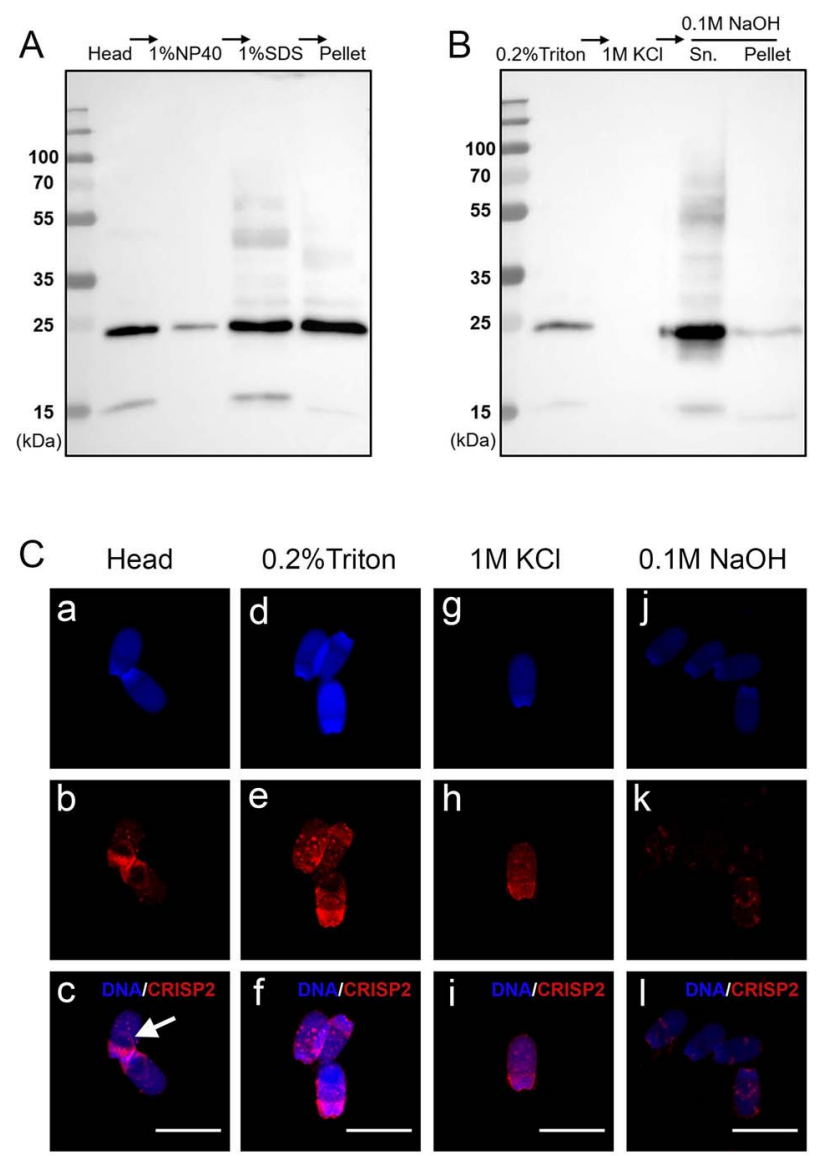

Figure 3. Biochemical characterization of CRISP2 from boar sperm head. (A) Detergent fractionation of sperm heads. Western blots of CRISP2 on the extracts of $1 \%$ NP- $40,1 \%$ SDS and the resulting pellet. The head lane was loaded as control to shows the presence of $\sim 25 \mathrm{kDa}$ CRISP2 in the sperm head. (B) Extraction of perinuclear theca (PT) proteins from sperm heads. Western blots of CRISP2 on the extracts of $0.2 \%$ Triton $\mathrm{X}-100,1 \mathrm{M} \mathrm{KCl}, 0.1 \mathrm{M}$ $\mathrm{NaOH}$ and the resulting pellet. (C) Immunofluorescent staining of CRISP2 on the sperm head and the resulting pellets from $0.2 \%$ Triton $\mathrm{X}-100,1 \mathrm{M}$ $\mathrm{KCl}, 0.1 \mathrm{M} \mathrm{NaOH}$. Extra labeling of CRISP2 was observed at the equatorial segments (arrow) of the head after sonication. (a, d, g and j) Hoechst 33342 staining. (b, e, h and k) CRISP2 immune labeling. ( $c, f, i$ and $I$ ) merged signals. The distance bar $=10 \mu \mathrm{m}$.

and $1.8 \%$ methylcellulose was used to pick up the ultrathin cryosections $(60 \mathrm{~nm})$. CRISP2 was detected by using the rabbit polyclonal antibody against CRISP2 (Cat\#: 19066-1-A, Proteintech, Chicago, IL, USA) detected by $10 \mathrm{~nm}$ Protein A coupled gold particles (Cell Microscopy Core, UMC Utrecht, the Netherlands). Stained with $2 \%$ uranyl acetate oxalate and $0.4 \%$ uranyl acetate in methylcellulose to increase contrast. EM imaging was done using a JEOL 1011 microscope.

\section{Results}

Characterization of CRISP2 in boar sperm heads and tails

Immunoblotting of extracts from whole sperm cells under reducing conditions showed CRISP2 detected across multiple protein bands besides the expected monomeric molecular weight of $\sim 25 \mathrm{kDa}$ (Figure 1A). The specificity of the primary antibody was validated by both pre-blocking using the epitope peptide or by primary antibody omission, and in both cases no positive signal was observed on Western blots (Figure 1A). Interestingly, further immunoblotting on purified sperm heads and tails revealed that the three higher molecular weight (MW) CRISP2 bands ( 100, 50, 35 kDa) were exclusively and consistently present in the sperm tail fractions, while the $\sim 25 \mathrm{kDa}$ monomer only resided in sperm heads (Figure 1A). When non-reducing conditions were used, the $\sim 25 \mathrm{kDa}$ was not visible while a high MW CRISP2 band ( $\sim 250 \mathrm{kDa}$ ) was observed in the sperm head fraction. Under the same non-reducing conditions, the $\sim 35$ and $\sim 100 \mathrm{kDa}$ bands in the whole sperm cell and tail fraction were no longer detected, however, the $\sim 50 \mathrm{kDa}$ remained (Figure 1B). It is likely that the 35 and $100 \mathrm{kDa}$ bands, only visible under reducing conditions, were originally present in the higher molecular weight complexes shown in Figure $1 \mathrm{~B}$ and C. The reduction of disulfide bridges (CRISP2 is highly enriched in cysteine residues) may be the driving force to allow this dissociation of CRISP2 from CRISP2-containing higher MW protein complexes. The $50 \mathrm{kDa}$ form appears to be $\beta$-mercapto-ethanol insensitive, which may indicate that another type of covalent interaction of CRISP2 is involved which is independent of disulfide bridge reduction. Note that CRISP2 is a CAP family member and has been reported to have amyloid forming properties [31]. In parallel to the western blots of Figure 1 complimentary SDS-PAGE gels were stained with Coomassie blue to show the total protein loading for whole sperm and the tail and head subfractions (Supplementary Figure S1). Here, we observed that under non-reducing conditions the signal at the top of the gel was increased $(>250 \mathrm{kDa})$, as well as two bands at $\sim 50$ and $\sim 45 \mathrm{kDa}$ (Supplementary Figure S1A). Under native conditions, CRISP2 migrated to $\sim 300-1000 \mathrm{kDa}$ protein complexes in the whole sperm and in the sperm head; while CRISP2 was involved in two complexes, $\sim 150$ and $\sim 200 \mathrm{kDa}$, in the tail fraction. The latter band was also present in low amounts in the whole sperm lane as well as in the sperm head fraction (Figure 1C). Again, specificity of the primary antibody was validated by preincubating with specific blocking peptide (data not shown). The purity of the sperm heads ( $>99 \%$ ) versus tail fractions (>95\%) from sonicated sperm samples were scored by phase-contrast microscopy (Supplementary Figure S2).

\section{Localization of CRISP2 in boar sperm}

Previous studies have reported that CRISP2 was localized in the sperm acrosome, connecting piece and the outer dense fibers of the sperm tail in human, mouse and rat $[21,23,24]$. In our study, CRISP2 was localized in boar sperm by indirect immunofluorescent staining of either non-permeabilized or permeabilized sperm samples. Only boundary labeling between the post-acrosomal region and the equatorial segment was observed in non-permeabilized sperm cells. However, strong CRISP2 labeling was acquired after permeabilization in both the post-acrosomal region and the connecting piece indicating that CRISP2 is predominantly localized intracellular in the sperm (Figure 2).

\section{CRISP2 in the perinuclear theca of the sperm head}

We focused first on the localization of CRISP2 in the post acrosomal region of sperm head. The solubility of CRISP2 was determined in the sperm head fraction that was subjected to a successive series of detergent fractionations. A small portion of $\sim 25 \mathrm{kDa}$ CRISP2 was able to be solubilized with 1\% NP-40 detergent and an additional portion of CRISP2 became solubilized after 1\% SDS extraction. 

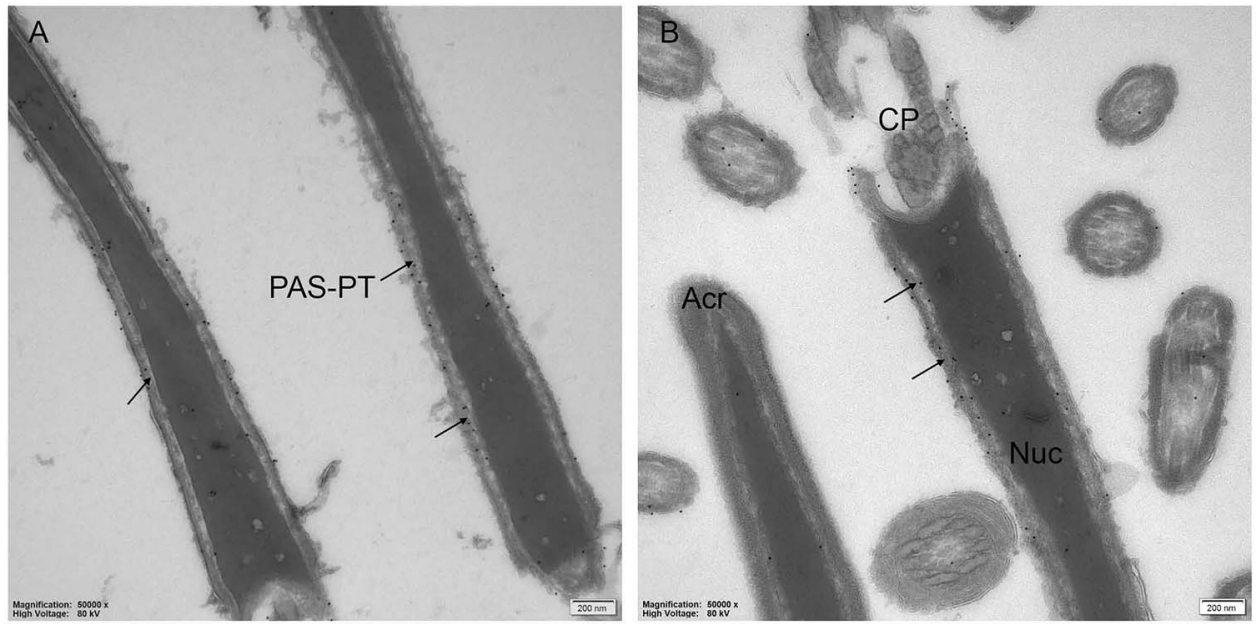

Figure 4. Ultrastructural localization of CRISP2 in boar spermatozoa. (A, B) Immunogold labeling of CRISP2 on sagittal sections through a whole sperm head showing that CRISP2 localized to the PAS-PT (arrow). (B) CRISP2 was not present in the Acrosome (cr) neither the Nucleus (Nuc). CP, connecting piece.

However, the majority of CRISP2 remained in the insoluble pellets after these successive extractions (Figure 3A). The fact that CRISP2 predominantly remained in the insoluble pellet after $1 \%$ NP-40 extraction suggests that CRISP2 might reside in the perinuclear theca (PT) structure of the sperm head. To confirm this, a standard procedure to isolate the proteins of the PT was performed in accordance with $[36,37]$. The CRISP2 containing sperm head fraction was first subjected to $0.2 \%$ Triton X-100 and only a small portion of CRISP2 was solubilized (Figure $3 \mathrm{~B}$ ) the subsequent treatment with $1 \mathrm{M} \mathrm{KCl}$ did not lead to any solubilization of CRISP2 while the $0.1 \mathrm{M}$ $\mathrm{NaOH}$ treatment almost completely solubilized CRISP2 such that CRISP2 was barely detectable in the cell pellet but abundant in the supernatant (Figure 3B). This is in line to the solubilization behavior of PT proteins as reported previously [39]. Coomassie blue staining of SDS-PAGE gels were performed to show protein extractability in different detergents (Supplementary Figure S3A, B). It was noted that a $\sim 15 \mathrm{kDa}$ was consistently present on the immunoblots of whole sperm cells (Figure 1A) and sperm head fractions (Figure 1B and Figure $3 \mathrm{~A}$ and $\mathrm{B})$. The $\sim 15 \mathrm{kDa}$ band labeling was able to be blocked by the blocking peptide (Figure 1A) indicating that it is a specific product from CRISP2. Moreover, it seems that this $\sim 15 \mathrm{kDa}$ was specifically from the head fraction and not the tail (Figure $1 \mathrm{~A}$ and $\mathrm{B}$ ). The $\sim 15 \mathrm{kDa}$ is the size of CAP domain of CRISP2. This may indicate that PMSF-sensitive serine proteases do not cleave the hinge connecting the CAP and c-terminal cysteinerich domain. Immunostaining on isolated sperm heads confirmed the predominant localization of CRISP2 in the post-acrosomal region and its PT specific solubilization behavior (Figure 3C). Note that $0.2 \%$ Triton X-100 revealed some additional staining of CRISP2 possibly from an intra-acrosomal origin (Figure 3C, arrowed). To complement these findings, immunogold labeling of CRISP2 was performed to show the intracellular ultra-localization of CRISP2 using transmission EM on ultrathin cryo-coupes of boar sperm. The best working antibody against CRISP2 for this technique was a Rabbit polyclonal. Immunofluorescent staining of permeabilized boar sperm confirmed that this rabbit anti-CRISP2 antibody also labeled the post acrosomal region and connecting piece of the sperm cells (Supplementary Figure S4A). Furthermore, immunofluorescent staining of ultrathin sperm sections revealed the same staining pattern (Supplementary Figure S4B). Indirect immunogold labeling using anti-CRISP2 antibody together with colloidal gold conjugated protein $G$ revealed that the gold particles were specifically localized to the perinuclear theca between the plasma membrane and the nuclear envelop (Figure 4).

\section{CRISP2 is present in both the outer dense fibers and fibrous sheath of the sperm tail}

As described above, beyond its presence in the sperm head, CRISP2 was also present in the sperm tail in three high $\mathrm{MW}$ multimers that were not observed in the sperm head. To gain more information about the subcellular localization and biochemical features of CRISP2, membrane fractionations of the tail were carried out. $1 \%$ Triton X-100 was used to solubilize membranes and the extrinsic and intrinsic membrane proteins that were not linked to cytoskeletal or extracellular matrix protein networks. SDS-EDTA effectively solubilizes the axoneme and plasma membrane, while it does not solubilize the connecting piece, the mitochondrial sheath, the outer dense fibers (ODF) and the fibrous sheath (FS) [40]. Immunoblotting of Triton X-100 extracted, as well as SDS-PAGE extracted, sperm tail fractions revealed that the three higher MW CRISP2 bands could be solubilized under these conditions (Figure 5A). However, in both cases multiple CRISP2 positive protein bands were detected in the insoluble pellet fractions with two prominent protein bands at $\sim 75$ and $\sim 55 \mathrm{kDa}$ (Figure 5A). The protein $\alpha$-tubulin was found in the Triton X-100 insoluble fraction, in contrast to its presence in the soluble fraction after SDS-EDTA treatment (Figure 5A). This profile of $\alpha$-tubulin detergent solubility in sperm tail fractions is in line with that reported in the literature [41, 42]. We noted that there was an additional protein band of $\sim 27 \mathrm{kDa}$ (clearly different in molecular weight from the $\sim 25 \mathrm{kDa}$ band that appeared after urea treatment). The $27 \mathrm{kDa}$ CRISP2 band was only observed in detergent extracts with SDS-EDTA, but not with Triton X-100 (Figure 5A). We, therefore, believe that the $\sim 27 \mathrm{kDa}$ was associated to insoluble tail material (in Figures 1 and 3 ) while it became solubilized specifically from the tail by SDS-EDTA treatment.

When sperm tail fractions were directly denatured in $2 \times$ SDS sample buffer, all CRISP2 protein bands described above were present (Figure 5B). However, treatment with $8 \mathrm{M}$ urea, resulted in a high -but not complete- dissociation of all higher MW bands into the $25 \mathrm{kDa}$ monomeric form with the exception of the $\sim 35 \mathrm{kDa}$ protein 

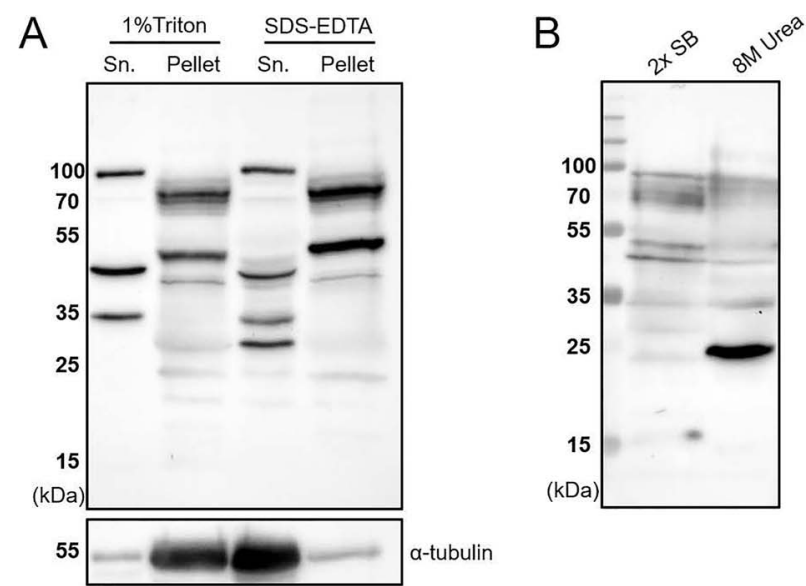

\section{C}
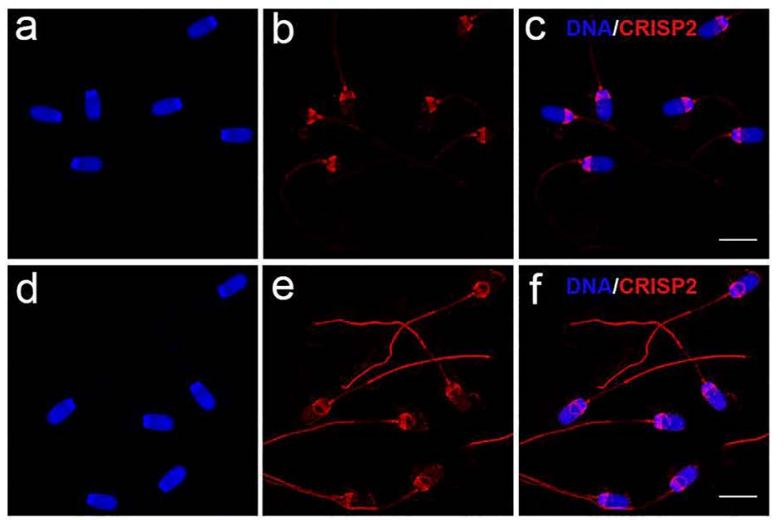

Figure 5. CRISP2 is present in different $\beta \mathrm{ME}$ resistant protein bands in sperm tails. (A) Western blots of CRISP2 on 1\% Triton and SDS-EDTA treated soluble and insoluble fractions. $\alpha$-tubulin was used to indicate the different solubility of sperm tails in these two detergents. (B) $8 \mathrm{M}$ urea treatment in sperm tails resulted in the dissociation of higher MW bands into the $25 \mathrm{kDa}$ monomeric form. (C) (a-c) Percoll washed sperm cells were fixed in 4\% PFA and permeabilized in $0.01 \%(\mathrm{w} / \mathrm{v})$ Saponin for $15 \mathrm{~min}$, at RT. $0.01 \%(\mathrm{w} / \mathrm{v})$ Saponin was used all along the following steps. (a) Hoechst 33342 staining. (b) CRISP2 immune labeling. (c) Merge of a and b. (d-f) Percoll washed sperm cells were first permeabilized in $0.01 \%(\mathrm{w} / \mathrm{v})$ saponin for $15 \mathrm{~min}$, at RT, then fixed in 4\% PFA. (d) Hoechst 33342 staining, (e) CRISP2 immune labeling. (f) Merge $d$ and e. The distance bar $=10 \mu \mathrm{m}$.

band (Figure 5B). Using PNGase F to digest the tail lysate did not result in the truncation of the $\sim 35 \mathrm{kDa}$ band. This may suggest that the porcine $35 \mathrm{kDa}$ band is a splice variant expressed by the same gene as the $25 \mathrm{kDa}$ band. However, this remains to be confirmed. It is also important to note that a $35-\mathrm{kDa}$-positive band for CRISP2 has been previously detected in transfected HEK293 cells transiently expressing human CRISP2 with the antibodies used in this study (see on product information sheets the property of both antibodies to variants of the same protein at https://www.novusbio.com/pro ducts/crisp-2-antibody_nbp1-52012 and at https://www.mybiosou rce.com/polyclonal-cow-dog-human-pig-antibody/crisp2/422304) Coomassie blue stained gels run in parallel to immunoblots revealed protein band molecular weights shifted in the $2 \times \mathrm{SB}$ and $8 \mathrm{M}$ urea conditions and that both lanes contained the same protein load (Supplementary Figure S5). CRISP2 immunostaining of sperm that were first fixed and then permeabilized exhibited no labeling of the sperm tail while the sperm head and neck were labeled (Figure $5 \mathrm{Cb}$ ).
In contrast, sperm that were permeabilized with a low concentration of saponin prior to fixation revealed additional clear labeling in the principle piece of the tail and some labeling of the central part of the mid-piece (Figure 5Ce). Pre-fixation permeabilization has previously been used to improve specificity labeling of cytoskeleton structures [43]. It is likely that low concentrations of saponin permeabilization before fixation allows the antibody to recognize its epitope on the CRISP2 protein in the principle piece. Immunogold labeling of ultrathin cryosections of boar sperm tail cross sections further confirmed that CRISP2 labeling was found in the ODF, but not at the plasma membrane or mitochondria of the midpiece (Figure 6A and B). This is in agreement with the central staining of CRISP2 in the mid-piece (Figure $5 \mathrm{Ce}$ ). Beyond the ODF, CRISP2 labeling was also observed in the FS of the principle piece (Figure 6C). Longitudinal sections confirmed CRISP2 labeling in the FS and ODF, as well as the absence of labeling in other structures (Figure 6D).

\section{Discussion}

Cysteine-rich secretory proteins (CRISPs) have attracted much attention in the field of reproduction due to their roles in male fertility. However, a biochemical understanding of CRISP protein structures and functions is still lacking. Evolutionary analysis on CRISPs from mammals as well as reptile venoms revealed that they have a highly conserved scaffold structure, but with diverse biological functions that were influenced by selective pressure among sites and lineages $[5,44,45]$. The gene expression of CRISPs in the pig has been well studied and the expression of CRISP2 in the testis is confirmed, as described for other mammals [46, 47]. Porcine CRISP2 (UniProt ID: F1RPZ6) protein has a high sequence similarity to CRISP2 of other mammalian species: $80.7 \%$ to human (UniProt ID: P16562), 78.3\% to guinea pig (UniProt ID: Q60477) and 68.9\% to mouse (UniProt ID: P16563) based on UniProt alignment (http://www.uniprot.org).

\section{The perinuclear theca and CRISP2}

In our study, biochemical analysis and ultralocalization studies of boar spermatozoa revealed that CRISP2 is localized in the post acrosomal sheath region of mature boar sperm head and more specifically those that reside in the perinuclear theca (PT). The PT is a unique cytoskeletal scaffold structure that is resistant to sonication and non-ionic detergent extraction; where even disulfide bond-reducing agents fail to solubilize proteins from the PT [26, 48]. The PT has been reported to play a vital role in spermiogenesis but may also play a role in processes that occur postfertilization. In support of this theory, the PT has been reported to harbor molecules essential for oocyte activation and early embryo development [48-50]. The PT is assembled during the elongation phase of spermatid development, shortly after abundant CRISP2 protein expression can be detected in round spermatids [8, 26, 51]. Early studies have reported that a $25 \mathrm{kDa}$ protein is one of the dominant PT protein bands on gel electrophoresis [39, 52] and later CRISP2 was identified in the perforatorium, which is part of the PT in rat spermatozoa [21, 53].

It is known that CRISPs possess 10 out of 16 cysteine residues clustered in the $\mathrm{C}$-terminal domain and these cysteine residues are involved in disulfide bond formation [54]. Interestingly, CRISP2 was present in boar sperm heads as part of a $250 \mathrm{kDa}$ protein complex under non-reducing conditions while it was dissociated into $25 \mathrm{kDa}$ monomers under reducing conditions. The use of 

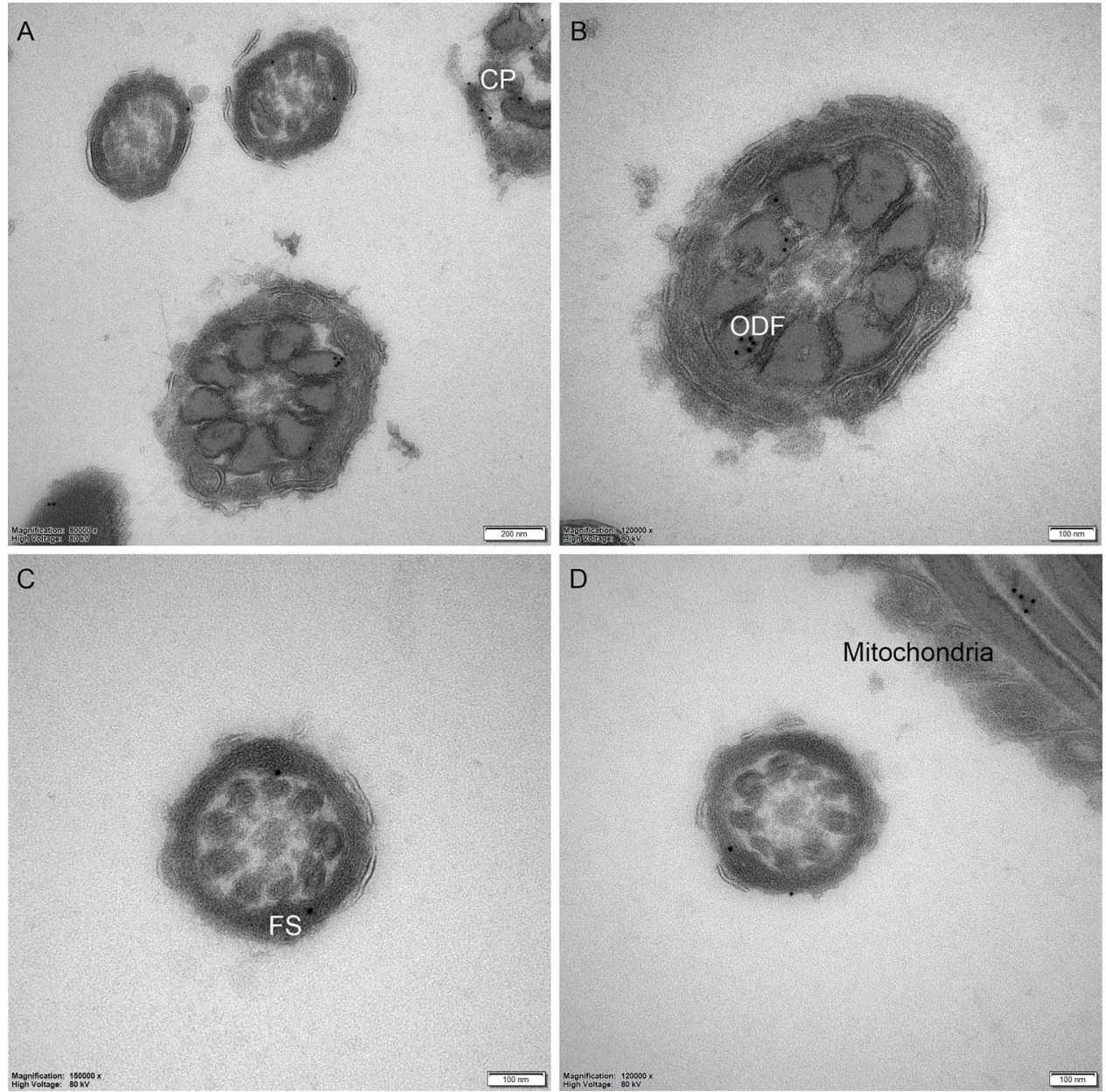

Figure 6. Ultrastructural localization of CRISP2 in boar sperm tail. (A) Immunogold labeling of CRISP2 on cross sections of the sperm tail showing that CRISP2 localized to the $\mathrm{CP}, \mathrm{ODF}$ and FS. (B) A cross section of the mid piece. (C) A cross section of the principle piece. (D) A longitudinal section showing that CRISP2 localized in the ODF, but absent in the mitochondria or the plasma membrane of the sperm tail. Supplementary Figure S1. Phase contrast microscopy of separated sperm heads and tails. Separated heads and tails were fixed in 4\% PFA for $15 \mathrm{~min}, \mathrm{RT} ; 20 \mu \mathrm{L}$ of the suspension was deposited on Super frost slides (Thermo Scientific) and covered with coverslips, then dried at RT for $20 \mathrm{~min}$. Images were collected using a 1.6×/20× objective OLYMPUS BX41 phase contrast microscopy. Distance bar $=10 \mu \mathrm{m}$.

$\beta$-mercapto-ethanol as a reducing agent results in the reduction of disulfide bridges between cysteine residues that are highly enriched in the cysteine rich domain of CRISP2. In theory, these reduced cysteine groups can both form intra- as well as inter- protein disulfide bridges. Thus, we propose that CRISP2 in the PT is organized into a $\sim 250 \mathrm{kDa}$ complex that is formed via covalent disulfide bridges between the participating proteins.

\section{CRISP2 in the sperm tail}

In the tail both the fibrous sheath (FS) and the outer dense fibers (ODF) are two condensed and highly insoluble protein structures which are unique to the mammalian sperm flagellum [40]. The protein composition of the FS and the ODF differ between different mammalian species, with three abundant proteins identified in isolated rat sperm FS and up to seven major proteins reported in rat sperm ODF [55-57]. Seven major protein bands have been revealed in human sperm FS [58] and two protein bands have been detected in human sperm ODF [59]. These FS protein bands are now known to consist of A-kinase anchoring proteins (AKAPs) AKAP3 and AKAP4 while ODF1 is the main and sole sperm-specific protein of the ODF [30, 60-62]. Importantly, Akap4 knock out male mice are infertile and Odf2 gene deletion resulted in abnormal sperm tails in the mouse $[63,64]$. In a case study on an infertile man it was found that AKAP4 was absent in the FS [65]. It is becoming clear that the FS and the ODF are not only simply structures regulating flagellum beating but are also more dynamically involved in sperm physiology, for example, in cell signaling and metabolism $[40,66]$.

Interestingly, in the sperm tail CRISP2 was present in $\sim 150$ and $\sim 200 \mathrm{kDa}$ protein complexes under native conditions. These CRISP2 containing protein complexes dissociated into three different $\beta$-mercapto-ethanol insoluble oligomeric forms. The three CRISP2 oligomers could be solubilized using more stringent detergent conditions (either $1 \%$ Triton X-100 or SDS-EDTA), in the presence of $\beta$-mercapto-ethanol; however, two oligomeric forms still remained insoluble (Figure 5A). Under reducing conditions, the sperm tail fraction contained all five oligomeric bands, while an $8 \mathrm{M}$ urea treatment caused a degree of dissociation of higher MW bands into $25 \mathrm{kDa}$ monomers. A combination of SDS sample buffer and $8 \mathrm{M}$ urea was used for efficient protein solubilization [67]. This 
behavior demonstrates that the oligomers in the sperm tail may interact in absence of covalent linkages, which is in contrast to CRISP2 oligomer bonding in the sperm head. Consistent with our study is the observation that in vitro recombinant mouse CRISP2 protein is involved in amyloid formation in the presence of $\mathrm{Zn}^{2+}$ [31]. It is possible that a $\mathrm{Zn}^{2+}$ interaction within CRISP2 and between CRISP2 or other proteins, is involved in the formation of reduction insensitive CRISP2 oligomers in the sperm tail. Moreover, we have demonstrated with other CAP family proteins that $\mathrm{Zn}^{2+}$ can result in the formation of amyloid oligomeric structures in vitro that depend on the CAP domain [31, 32]. The involvement of $\mathrm{Zn}^{2+}$ in establishing specific features of the sperm tail during epididymal sperm maturation has been reported previously [68, 69]. Moreover, most of sperm's $\mathrm{Zn}^{2+}$ has indeed been reported to reside in the ODF [70]. We propose here that the ODF and FS oligomeric formation of CRISP2 molecules may occur in the sperm tail in a similar way. Immunogold labeling confirmed that CRISP2 was localized in the FS, the ODF and the connecting piece. This is consistent with previous studies observing the same localization [21, 24]. No signals were observed in the mitochondria or at the plasma membrane, nor in the nucleus of the sperm.

In conclusion, this study reports for the first time the precise localization and biochemical features of CRISP2 in boar spermatozoa. We demonstrate that CRISP2 is present as a $300-1000-k D a$ oligomers in the sperm head perinuclear theca structure and that this oligomer is stabilized covalently by reduction sensitive disulfide bridges. In contrast in the sperm tail FS and ODF, five smaller oligomers of CRISP2 were detected that are largely reduction insensitive and likely dependent on the CAP domain.

We are currently working on unraveling the CRISP2 interactome in the sperm tail (in the ODF and FS) versus sperm head (in the PT). In part, there are expected to be differences in CRISP2-interacting proteins in the PT compared to the ODF and FS due to the specific protein composition and architecture of these regions. It is also possible that the oligomerization conditions in these structures also differ. For instance, local differences in redox balance (PT, in the head) or in $\mathrm{Zn}^{2+}$ levels (ODF, FS in the tail) may contribute to the differences noted in CRISP2 oligomers in the sperm head versus tail.

In CRISP2, loss of function models in mouse alterations in stiffness of the mid-piece and aberrant motility have been detected in sperm and consequently a subfertile phenotype was observed [17]. The fact that CRISP2 dimers are not sensitive to reducing agents may indicate that in the tail the $\mathrm{Zn}^{2+}$ dependent oligomerization into more amyloid like CRISP2 containing is taken place. In fact, $\mathrm{Zn}^{2+}$ levels have been described to change under capacitating conditions and this may well relate to altered motility properties of sperm [71]. It is yet unknown whether such $\mathrm{Zn}^{2+}$ changes will cause altered CRISP2 interactions in the ODF and FS and thus affect the elastic properties of these structures.

Additionally, our study shows that CRISP2 oligomers in the PT are very reduction sensitive. This aligns with previous reports for the mouse that demonstrate that the post acrosomal sheath (part of the PT) is rapidly broken down post-fertilization by glutathione-Stransferase omega 2 [72]. Given that this enzyme is also present in boar spermatozoa (identification after proteomic analysis of the PT; unpublished results), it may be involved in reducing the disulfide bridges of CRISP2 in the PT and alter CRISP2 containing high MW protein complexes [72]. The PT emerges as a well-formed and condensed structure during the elongation phase of spermatids and is supposed to be functional in protecting the pore free part of the nuclear envelope. Likely, the oxidation of free sulfhydryl groups in CRISP2 are involved in the condensation of the PT during late spermatid development until epididymal maturation [73] and this process has also been described for the formation of flagellar structures that are involved in sperm motility [33]. Future studies will be devoted to the role of CRISP2 (a known inducer of non-pathological protein amyloids) in sperm protein complex formation, the identity of any additional proteins in CRISP2 containing complexes, and the function of the different oligomeric CRISP2 organizations in the sperm head versus sperm tail in fertilization and post-fertilization processes.

\section{Supplementary material}

Supplementary material is available at BIOLRE online.

\section{References}

1. Gibbs GM, Roelants K, O’Bryan MK. The CAP superfamily: Cysteinerich secretory proteins, antigen 5 , and pathogenesis-related 1 proteinsroles in reproduction, cancer, and immune defense. Endocr Rev 2008; 29:865-897.

2. Gibbs GM, Lo JC, Nixon B, Jamsai D, O'Connor AE, Rijal S, SanchezPartida LG, Hearn MT, Bianco DM, O'Bryan MK. Glioma pathogenesisrelated 1-like 1 is testis enriched, dynamically modified, and redistributed during male germ cell maturation and has a potential role in sperm-oocyte binding. Endocrinology 2010; 151:2331-2342.

3. Gaikwad AS, Hu J, Chapple DG, O'Bryan MK. The functions of CAP superfamily proteins in mammalian fertility and disease. Human Reprod Update 2020; 26:689-723.

4. Fry BG, Casewell NR, Wüster W, Vidal N, Young B, Jackson TNW. The structural and functional diversification of the Toxicofera reptile venom system. Toxicon 2012; 60:434-448.

5. Tadokoro T, Modahl CM, Maenaka K, Aoki-Shioi N. Cysteine-rich secretory proteins (CRISPs) from venomous snakes: An overview of the functional diversity in a large and underappreciated superfamily. Toxins 2020; 12:175.

6. Jalkanen J, Huhtaniemi I, Poutanen M. Mouse cysteine-rich secretory protein 4 (CRISP4): A member of the CRISP family exclusively expressed in the epididymis in an androgen-dependent manner. Biol Reprod 2005; 72:1268-1274.

7. Vicens A, Trevino CL. Positive selection in the evolution of mammalian CRISPs. J Mol Evol 2018; 86:635-645.

8. Koppers AJ, Reddy T, O'Bryan MK. The role of cysteine-rich secretory proteins in male fertility. Asian J Androl 2011; 13:111-117.

9. Udby L, Bjartell A, Malm J, Egesten A, Lundwall A, Cowland JB, Borregaard N, Kjeldsen L. Characterization and localization of cysteine-rich secretory protein 3 (CRISP-3) in the human male reproductive tract. $J$ Androl 2005; 26:333-342.

10. Carvajal G, Brukman NG, Weigel Muñoz M, Battistone MA, Guazzone VA, Ikawa M, Haruhiko M, Lustig L, Breton S, Cuasnicu PS. Impaired male fertility and abnormal epididymal epithelium differentiation in mice lacking CRISP1 and CRISP4. Sci Rep 2018; 8:17531-17531.

11. Hu J, Merriner DJ, O'Connor AE, Houston BJ, Furic L, Hedger MP, O'Bryan MK. Epididymal cysteine-rich secretory proteins are required for epididymal sperm maturation and optimal sperm function. Mol Hum Reprod 2018; 24:111-122.

12. Pathak BR, Breed AA, Deshmukh P, Mahale SD. Androgen receptor mediated epigenetic regulation of CRISP3 promoter in prostate cancer cells. J Steroid Biochem Mol Biol 2018; 181:20-27.

13. Asmann YW, Kosari F, Wang K, Cheville JC, Vasmatzis G. Identification of differentially expressed genes in normal and malignant prostate by electronic profiling of expressed sequence tags. Cancer Res 2002; 62:3308-3314. 
14. Noh BJ, Sung JY, Kim YW, Chang SG, Park YK. Prognostic value of ERG, PTEN, CRISP3 and SPINK1 in predicting biochemical recurrence in prostate cancer. Oncol Lett 2016; 11:3621-3630.

15. Volpert M, Furic L, Hu J, O'Connor AE, Rebello RJ, Keerthikumar S, Evans J, Merriner DJ, Pedersen J, Risbridger GP, McIntyre P, O’Bryan MK. CRISP3 expression drives prostate cancer invasion and progression. Endocr Relat Cancer 2020; 27:415-430.

16. Brukman NG, Miyata H, Torres P, Lombardo D, Caramelo JJ, Ikawa M, Da Ros VG, Cuasnicu PS. Fertilization defects in sperm from cysteinerich secretory protein 2 (Crisp2) knockout mice: Implications for fertility disorders. Mol Hum Reprod 2016; 22:240-251.

17. Lim S, Kierzek M, O'Connor AE, Brenker C, Merriner DJ, Okuda H, Volpert M, Gaikwad A, Bianco D, Potter D, Prabhakar R, Strunker T et al. CRISP2 is a regulator of multiple aspects of sperm function and male fertility. Endocrinology 2019; 160:915-924.

18. Heidary Z, Zaki-Dizaji M, Saliminejad K, Khorramkhorshid HR. Expression analysis of the CRISP2, CATSPER1, PATE1 and SEMG1 in the sperm of men with idiopathic Asthenozoospermia. J Reprod Infertil 2019; 20:70-75.

19. Gholami D, Salman Yazdi R, Jami MS, Ghasemi S, Sadighi Gilani MA, Sadeghinia S, Teimori H. The expression of cysteine-rich secretory protein 2 (CRISP2) and miR-582-5p in seminal plasma fluid and spermatozoa of infertile men. Gene 2020; 730:144261.

20. Wang H, Zhou Z, Xu M, Li J, Xiao J, Xu ZY, Sha J. A spermatogenesisrelated gene expression profile in human spermatozoa and its potential clinical applications. J Mol Med (Berl) 2004; 82:317-324.

21. O’Bryan MK, Sebire K, Meinhardt A, Edgar K, Keah HH, Hearn MT, De Kretser DM. Tpx-1 is a component of the outer dense fibers and acrosome of rat spermatozoa. Mol Reprod Dev 2001; 58:116-125.

22. Haendler B, Habenicht UF, Schwidetzky U, Schuttke I, Schleuning WD. Differential androgen regulation of the murine genes for cysteine-rich secretory proteins (CRISP). Eur J Biochem 1997; 250:440-446.

23. Busso D, Cohen DJ, Hayashi M, Kasahara M, Cuasnicu PS. Human testicular protein TPX1/CRISP-2: Localization in spermatozoa, fate after capacitation and relevance for gamete interaction. Mol Hum Reprod 2005; 11:299-305.

24. Hardy DM, Huang TT Jr, Driscoll WJ, Tung KK, Wild GC. Purification and characterization of the primary acrosomal autoantigen of Guinea pig epididymal spermatozoa. Biol Reprod 1988; 38:423-437.

25. Oko RJ. Developmental expression and possible role of perinuclear theca proteins in mammalian spermatozoa. Reprod Fertil Dev 1995; 7:777-797.

26. Oko R, Sutovsky P. Biogenesis of sperm perinuclear theca and its role in sperm functional competence and fertilization. J Reprod Immunol 2009; $83: 2-7$.

27. Foster JA, Gerton GL. The Acrosomal matrix. Adv Anat Embryol Cell Biol 2016; 220:15-33.

28. Guyonnet B, Egge N, Cornwall GA. Functional amyloids in the mouse sperm acrosome. Mol Cell Biol 2014; 34: 2624-2634.

29. Oko R. Occurrence and formation of cytoskeletal proteins in mammalian spermatozoa. Andrologia 1998; 30:193-206.

30. Lehti MS, Sironen A. Formation and function of sperm tail structures in association with sperm motility defects. Biol Reprod 2017; 97: $522-536$.

31. Sheng J, Olrichs NK, Geerts WJ, Li X, Rehman AU, Gadella BM, Kaloyanova DV, Helms JB. Zinc binding regulates amyloid-like aggregation of GAPR-1. Biosci Rep 2019; 39:BSR20182345.

32. Sheng J, Olrichs NK, Gadella BM, Kaloyanova DV, Helms JB. Regulation of functional protein aggregation by multiple factors: Implications for the Amyloidogenic behavior of the CAP superfamily proteins. Int J Mol Sci 2020; 21:6530.

33. Cabrillana ME, Monclus MA, Sáez Lancellotti TE, Boarelli PV, Clementi MA, Vincenti AE, Yunes RFM, Fornés MW. Characterization of flagellar cysteine-rich sperm proteins involved in motility, by the combination of cellular fractionation, fluorescence detection, and mass spectrometry analysis. Cytoskeleton 2011; 68:491-500.
34. Moghadam M, Ganji A, Varasteh A, Falak R, Sankian M. Refolding process of cysteine-rich proteins: Chitinase as a model. Rep Biochem Mol Biol 2015; 4:19-24.

35. Sheng J, Olrichs NK, Geerts WJ, Kaloyanova DV, Helms JB. Metal ions and redox balance regulate distinct amyloid-like aggregation pathways of GAPR-1. Sci Rep 2019; 9:15048.

36. Oko R, Aarabi M, Mao J, Balakier H, Sutovsky P. Sperm-specific WWdomain-binding proteins. In: De Jonge CJ, Barratt CLR (eds.), The Sperm Cell: Production, Maturation, Fertilization, Regeneration, 2nd ed. Cambridge: Cambridge University Press; 2017: 157-176.

37. Hamilton LE, Acteau G, Xu W, Sutovsky P, Oko R. The developmental origin and compartmentalization of glutathione-s-transferase omega 2 isoforms in the perinuclear theca of eutherian spermatozoa. Biol Reprod 2017; 97:612-621.

38. Slot JW, Geuze HJ. Cryosectioning and immunolabeling. Nat Protoc 2007; 2:2480-2491

39. Oko R, Maravei D. Protein composition of the perinuclear theca of bull spermatozoa. Biol Reprod 1994; 50:1000-1014.

40. Cao WL, Gerton GL, Moss SB. Proteomic profiling of accessory structures from the mouse sperm flagellum. Mol Cell Proteomics 2006; 5:801-810.

41. Zhou J, Yang F, Leu NA, Wang PJ. MNS1 is essential for spermiogenesis and motile ciliary functions in mice. PLoS Genet 2012; 8:e1002516e1002516.

42. Kwon JT, Ham S, Jeon S, Kim Y, Oh S, Cho C. Expression of uncharacterized male germ cell-specific genes and discovery of novel sperm-tail proteins in mice. PLoS One 2017; 12:e0128208.

43. Zong S, Chen C, Zhang Y, Li L, Wang Z, Cui Y. An innovative strategy to obtain extraordinary specificity in immunofluorescent labeling and optical super resolution imaging of microtubules. RSC Adv 2017; 7:39977-39988.

44. Arevalo L, Brukman NG, Cuasnicu PS, Roldan ERS. Evolutionary analysis of genes coding for cysteine-RIch secretory proteins (CRISPs) in mammals. BMC Evol Biol 2020; 20:67.

45. Sunagar K, Johnson WE, O’Brien SJ, Vasconcelos V, Antunes A. Evolution of CRISPs associated with toxicoferan-reptilian venom and mammalian reproduction. Mol Biol Evol 2012; 29:1807-1822.

46. Song CY, Gao B, Wu H, Wang XY, Zhou HY, Wang SZ, Li BC, Chen GH, Mao JD. Spatial and temporal gene expression of Fn-type II and cysteinerich secretory proteins in the reproductive tracts and ejaculated sperm of Chinese Meishan pigs. Reprod Domest Anim 2011; 46:848-853.

47. Vadnais ML, Foster DN, Roberts KP. Molecular cloning and expression of the CRISP family of proteins in the boar. Biol Reprod 2008; 79:1129-1134.

48. Sutovsky P, Oko R, Hewitson L, Schatten G. The removal of the sperm perinuclear theca and its association with the bovine oocyte surface during fertilization. Dev Biol 1997; 188:75-84.

49. Sutovsky P, Manandhar G, Wu A, Oko R. Interactions of sperm perinuclear theca with the oocyte: Implications for oocyte activation, antipolyspermy defense, and assisted reproduction. Microsc Res Tech 2003; 61:362-378.

50. Hamilton LE, Suzuki J, Acteau G, Shi M, Xu W, Meinsohn MC, Sutovsky P, Oko R. WBP2 shares a common location in mouse spermatozoa with WBP2NL/PAWP and like its descendent is a candidate mouse oocyteactivating factor. Biol Reprod 2018; 99:1171-1183.

51. Foster JA, Gerton GL. Autoantigen 1 of the Guinea pig sperm acrosome is the homologue of mouse Tpx-1 and human TPX1 and is a member of the cysteine-rich secretory protein (CRISP) family. Mol Reprod Dev 1996; 44:221-229.

52. Korley R, Pouresmaeili F, Oko R. Analysis of the protein composition of the mouse sperm perinuclear theca and characterization of its major protein Constituent1. Biol Reprod 1997; 57:1426-1432.

53. Oko R, Clermont Y. Isolation, structure and protein composition of the perforatorium of rat spermatozoa. Biol Reprod 1988; 39:673-687.

54. Gibbs GM, Scanlon MJ, Swarbrick J, Curtis S, Gallant E, Dulhunty AF, O'Bryan MK. The cysteine-rich secretory protein domain of Tpx-1 is related to ion channel toxins and regulates ryanodine receptor $\mathrm{Ca} 2+$ Signaling. J Biol Chem 2006; 281:4156-4163. 
55. Oko R. Comparative analysis of proteins from the fibrous sheath and outer dense Fibers of rat Spermatozoa1. Biol Reprod 1988; 39:169-182.

56. Olson GE, Sammons DW. Structural chemistry of outer dense Fibers of rat Sperm1. Biol Reprod 1980; 22:319-332.

57. Vera JC, Brito M, Zuvic T, Burzio LO. Polypeptide composition of rat sperm outer dense fibers. A simple procedure to isolate the fibrillar complex. J Biol Chem 1984; 259:5970-5977.

58. Jassim A, Gillott DJ, Al-Zuhdi Y, Gray A, Foxon R, Bottazzo GF. Isolation and biochemical characterization of the human sperm tail fibrous sheath. Hum Reprod 1992; 7:86-94.

59. Henkel R, Stalf T, Mertens N, Miska W, Schill WB. Outer dense fibres of human spermatozoa: Partial characterization and possible physiological functions. Int J Androl 1994; 17:68-73.

60. Brown PR, Miki K, Harper DB, Eddy EM. A-kinase anchoring protein 4 binding proteins in the fibrous sheath of the sperm flagellum. Biol Reprod 2003; 68:2241-2248.

61. Eddy EM, Toshimori K, O'Brien DA. Fibrous sheath of mammalian spermatozoa. Microsc Res Tech 2003; 61:103-115.

62. Hetherington L, Schneider EK, Scott C, DeKretser D, Muller CH, Hondermarck H, Velkov T, Baker MA. Deficiency in outer dense Fiber 1 is a marker and potential driver of idiopathic male. Inf Dent 2016; 15:3685-3693.

63. Fang X, Huang L-L, Xu J, Ma C-Q, Chen Z-H, Zhang Z, Liao C-H, Zheng S-X, Huang P, Xu W-M, Li N, Sun L. Proteomics and single-cell RNA analysis of Akap4-knockout mice model confirm indispensable role of Akap4 in spermatogenesis. Dev Biol 2019; 454:118-127.

64. Tarnasky H, Cheng M, Ou Y, Thundathil JC, Oko R, van der Hoorn FA. Gene trap mutation of murine outer dense fiber protein-2 gene can result in sperm tail abnormalities in mice with high percentage chimaerism. BMC Dev Biol 2010; 10:67.

65. Baccetti B, Collodel G, Estenoz M, Manca D, Moretti E, Piomboni P. Gene deletions in an infertile man with sperm fibrous sheath dysplasia. Hum Reprod 2005; 20:2790-2794.

66. Amaral A, Castillo J, Estanyol JM, Ballescà JL, Ramalho-Santos J, Oliva R. Human Sperm Tail Proteome Suggests New Endogenous Metabolic Pathways, vol. 12. 2013: 330-342.

67. Peach M, Marsh N, Miskiewicz EI, MacPhee DJ. Solubilization of proteins: The importance of lysis buffer choice. Methods Mol Biol 2015; 1312:49-60.

68. Baccetti B, Pallini V, Burrini AG. The accessory fibers of the sperm tail. II. Their role in binding zinc in mammals and cephalopods. J Ultrastruct Res 1976; 54:261-275.

69. Henkel R, Baldauf C, Bittner J, Weidner W, Miska W. Elimination of zinc from the flagella of spermatozoa during epididymal transit is important for motility. Reproductive Technology 2001; 10:280-285.

70. Bertelsmann H, Sieme H, Behne D, Kyriakopoulos A. Is the distribution of selenium and zinc in the sublocations of spermatozoa regulated? Ann N Y Acad Sci 2007; 1095:204-208.

71. Kerns K, Zigo M, Drobnis EZ, Sutovsky M, Sutovsky P. Zinc ion flux during mammalian sperm capacitation. Nat Commun 2018; 9:2061.

72. Hamilton LE, Suzuki J, Aguila L, Meinsohn MC, Smith OE, Protopapas $\mathrm{N}, \mathrm{Xu}$ W, Sutovsky P, Oko R. Sperm-borne glutathione-S-transferase omega 2 accelerates the nuclear decondensation of spermatozoa during fertilization in mice†. Biol Reprod 2019; 101:368-376.

73. Fujii J, Tsunoda S. Redox regulation of fertilisation and the spermatogenic process. Asian J Androl 2011; 13:420-423. 